Form, Matter, Substance by Kathrin Koslicki, Oxford: Oxford University Press, 2018. Pp. xiii +273.

Kathrin Koslicki's book Form, Matter, Substance is a clear, rigorous, and stimulating study of central issues in metaphysics discussed through the so-called 'Neo-Aristotelian' perspective.

Koslicki detects a tension between Aristotle's ontology in the Categories -which she takes to be a 'blob' (non-reductive) ontology- and his later hylomorphic picture, which conceives particular substances as matter-form compounds. In her view of Aristotelian hylomorphism, the form is a part of the compound alongside its material parts (using one single sense of 'being a part'). She specifies the matter-form relation (one of the three 'hylomorphic relations' she distinguishes; p. 104) in terms of what she calls 'Robust Mereological Hylomorphic Pluralism' (RMHP). First, in line with her view of form as a part alongside material parts, she takes the matter-form relation as a type of mereological composition. Second, she favours robust hylomorphic pluralism. The form is a robust particular which cannot be analysed in reductive terms. Nor can it be specified using minimal conditions which could be satisfied even by the matter constituting a compound just in virtue of the matter's being spatiotemporally coincident with that compound. Thus, it does not follow from the fact that a compound's constituent matter is spatiotemporally coincident with it, and so has the same structure, arrangement, or organisation as it does, that the matter, too, has the same form. Rather, the constituent matter has a different form of its own, and so is numerically distinct from the compound. This pluralist aspect of her view denies the monist idea that no two numerically distinct objects can be spatiotemporally coincident. Rather, in her hylomorphic picture, despite being spatiotemporally coincident, the compound and its constituent matter are two numerically distinct objects with corresponding different essences. 
Indeed, each is a particular object and a hylomorphic compound. There is no difference between them in respect of ontological category. As a result, she views a compound's material components as subject to a similar, hylomorphic and hierarchical picture:

'The material parts of matter-form compounds are themselves matter-form compounds, unless or until we reach an empirically confirmed level in the compositional hierarchy at which the material parts of matter-form compounds are not themselves structured wholes'. (p. 59)

A major part of her book focuses on the individual versus universal form debate. Koslicki firmly places herself in the individual form camp, mainly for reasons related to the possibility of identifying a particular matter-form compound in other possible worlds.

In the second part of her book Koslicki discusses whether and how, despite the analysis of particular substances into matter and form, we could retain their fundamentality as substances. The difficulty she diagnoses runs as follows:

(1) Particular substances are matter-form compounds.

(2) A basic substancehood criterion is independence.

(3) Particular hylomorphic compounds are (or should qualify as) substances.

If we insist on the importance of the independence criterion for substancehood (2) and, at the same time, maintain that particular compounds depend on form and/or matter, as is suggested by (1), it is hard to see how they can qualify as substances (3). After an illuminating discussion of the main alternative construals of the independence criterion, Koslicki proposes to resolve this problem by discarding this criterion altogether. She argues that it is a hopeless task to seek to render particular hylomorphic compounds substances on the basis of an independence substancehood criterion. Rather, she contends, it is more promising to favour unity as a substancehood criterion: for unity, if properly understood, does indeed render hylomorphic compounds more suitable for the title of substance if compared with cases such 
as sets, heaps, or even artefacts. In a nutshell, her account of unity -what she calls 'lawful generic interactional interdependence' - runs as follows: the material parts of an integrated whole have 'contributing' capacities which co-depend: each part's contributing capacity(ies) depend(s) on some but not all other parts' contributing capacities and the related manifestations. By contrast, the compound whole has 'team-work-requiring' capacities which are enabled by the contributing capacities of its constituents.

In what follows I shall raise two questions about Koslicki's position. I shall not assess her arguments as putative interpretations of Aristotle's texts as she is clear that her goals are not narrowly exegetical.

\section{Individual Forms}

The universal versus individual form debate is the main issue Koslicki examines in the part of her book dedicated to form. She starts by discussing the universal form approach and examines several options as to what sort of entity a universal form might be. She lists properties or relations, powers, activities, acts of creation, or sui generis universal entities. There is a question of exhaustiveness or exclusiveness at this juncture. Let us focus on exclusiveness: might it be possible to combine some of these options? For instance, we may think that forms fall under the general heading of property-like entities but consist in powers, capacities, faculties, or even actualities of a certain sort. For instance, Aristotle identifies second-level potentialities with first-level actualities: the mental state of geometrical knowledge (a potentiality) seems to be the same as actually possessing geometrical knowledge and being able to use it without any further change. Koslicki agrees that these options are combinable, and indeed are combined by several theorists. Moreover, as she points out, the options she lists are neutral as between the universal or the individual form 
view. For even the proponents of individual forms will have to say what their forms are, and will have to choose some or other among the very same options.

Unfortunately, Koslicki does not commit to any definite ontological view about her individual forms. Her main point is that forms are robust particulars which are parts of the compound and also figure in the compound's essence -either by exhausting or by being prominent parts of its essence. But more specificity would be desirable. Are they objects? Are they souls in the sense of a 'spirit' that inhabits and enlivens a body? Are they processes, events, facts, states of affairs? Perhaps neutrality is a virtue. It may be thought attractive that her version of hylomorphism is compatible with a wide variety of divergent hylomorphic views with stronger commitments as to what forms are (p. 243).

What is the motivation for favouring individual forms? What are the conceptual problems that this view alone can resolve? Koslicki's main argument is that only individual forms can underwrite the possibility of cross-world identification of particular hylomorphic compounds. Briefly: in her view, Socrates in the actual world, $w$, is identical with Socrates in another possible world, $w_{1}$, in virtue of the individual form, his very own soul, being the same across $w$ and $w_{1}$. While she takes this sort of cross-world numerical sameness of individual forms and so their 'identificatory power' as basic facts, she makes the following two clarifications:

(1) Individual forms impose qualitative constraints on the hylomorphic compounds with which they are associated.

(2) These qualitative constraints are not merely about contingent states of affairs. For example, Socrates' individual form, his soul, does not impose the qualitative constraint that his nose be snub. Rather, it dictates non-contingent constraints such as that his bodily parts be structured in the manner characteristic of members of the human kind, that he be rational, that he be capable of learning things, etc. The locus of this constraint-imposing 
function of individual forms seems to be their being actual parts constituting the hylomorphic compound alongside its material parts in the manner of mereological composition. In constituting the compound in this way, individual forms structure its material components in the constraint-imposing way. But what is the source of such qualitative constraints? Does each individual form contain such constraints in its own right, or does it 'inherit' them, as it were, from a corresponding universal item under which it falls or which it instantiates? And if the latter is the case, what do we gain by positing individual forms? We cannot invoke any references to Socrates himself or use demonstratives (for example, 'this form' or 'the form of this body') to identify Socrates or his individual form across possible worlds, for this would be circular.

Koslicki's reply would presumably be that her individual forms can face the challenge raised by Alan Sidelle ('Does Hylomorphism Offer a Distinctive Solution to the Grounding Problem?', Analysis 74(3), 2014, 397-404) far better than the alternatives. Sidelle's challenge can be formulated as a dilemma, both horns of which are unpalatable for the hylomorphist. The challenge is that hylomorphists should be able to offer a satisfactory solution to the grounding problem but they cannot do so. The grounding problem is the question of what grounds the difference between the matter and the compound despite the fact that they are spatiotemporally coincident objects. The first horn of Sidelle's challenge is that the hylomorphist might give no answer to this problem: for he/she might respond that the form belongs essentially to the compound but only contingently to the matter. But, if so, Sidelle asks, how can the same form bear exactly the same relation of belonging (or being predicated) in these two different ways? If we reply that this is so just because the matter is different from the compound, we are offering a merely circular response and so not a genuine answer at all to the grounding problem. In the second horn, by contrast, hylomorphists do not follow this approach but are bound to give no distinctively hylomorphic answer to the 
grounding problem. They contend that there are two different forms, the one of the compound (e.g., the statue) the other of the matter (e.g., the clay). But, Sidelle argues, this sort of response is shared by hylomorphists and non-hylomorphists alike. Moreover, it does not constitute a satisfactory answer to the grounding problem (p. 108-109).

Koslicki maintains that her individual form view has a better response to this problem. Her first move is to deploy her non-modal conception of essence: she holds that the different essences of the matter and of the compound will explain different derivative, necessary but non-essential features. These different features will presumably give a non-ad hoc grounding of the difference between the spatiotemporally coincident matter and compound. This avoids the first horn of Sidelle's challenge. In addressing the second horn of this challenge, Koslicki follows a roughly primitivist approach. She holds that it is a basic fact that the matter and the compound are numerically distinct objects with different essences. As Koslicki makes clear, these two moves are neither peculiar to her approach nor distinctively hylomorphic. Most plausible views of the relation between Aristotelian essences and modality agree that merely modal features of objects are explained or caused (not merely logically entailed) by their essence. The converse is not the case. Furthermore, while hylomorphists identify form with essence and aim to offer metaphysical explanations (such as the answer to the grounding problem) ultimately on the basis of form, non-hylomorphists too (at least some of them) argue that different essences will ground the difference of numerically distinct objects (even if these thinkers do not identify those essences with forms).

Here is another way to undermine Sidelle's challenge, which neither invokes individual forms nor indeed commits to any specific answer to the question 'are forms universal or individual?'. If we deploy the causal-explanatory model developed in Metaphysics Z.17-H, at least in the way some of us understand it (see, e.g., Peramatzis M. (2018), ‘Aristotle's Hylomorphism: The Causal-Explanatory Model'. Metaphysics. 1(1), 12 
32. DOI: http://doi.org/10.5334/met.2), the form becomes the basic essence, cause, and determinant of the matter and the compound. The matter by itself, in contrast, is merely determinable (or like a determinable). Determinables, however, are not proper objects but are abstractions of some sort, and so do not, strictly speaking, possess intrinsic properties at all, whether essentially or contingently. Presumably, determinables have mere Cambridge properties. Moreover, they have the properties ascribed to them by a (correct) theory of determinables, determinates, and determinants or any other similar 'theoretical' properties. Similarly, they have properties insofar as they are abstract items. Compare how Platonist Forms have theoretical properties within the theory of Forms (insofar as they are just Forms) such as being intelligible, imperceptible, separate, etc. Yet, at least according to the Platonist, this does not render them particulars that participate in any extra 'super-Forms'. Similarly, thinkers who subscribe to bare particulars theorise about them and attribute theoretical properties to them without thereby making them non-bare particulars.

If matter by itself is, or is like, a determinable, the first horn of Sidelle's challenge could be avoided as follows. Matter by itself is not merely contingently related to the form, for it is not by itself a proper object at all. If so, nothing (intrinsically) belongs to it (whether essentially or contingently). This suggests that, properly speaking, there is only one object, Socrates, whereas the matter by itself is not yet a proper object at all. There is only a trivial, unproblematic sense in which matter $\neq$ compound as the former is a determinable, whereas the latter is a determinate. If, on the other hand, the matter we are referring to is the matter which is thus-and-so enformed -e.g., Socrates' body structured and alive in the same way as Socrates- there is no reason to draw any distinction between it and the compound, Socrates. There are not two different but spatiotemporally coincident objects. Rather, there is just one object: the compound or, in another mode of description, the matter thus-and-so enformed. Clearly, there are different ways to speak of matter. Bricks, mortar, stones, etc. may be 
deemed material from the perspective of the completed house. Yet they are fully enformed compound objects, artefacts of some sort. Similarly, a human corpse is a compound with the merely 'chemical', as it were, form of a carcass (as opposed to the 'biological' form of being a human). But such cases, I submit, are not merely material items or matter by itself; nor are they (like) determinables. Rather, they are determinate compounds, fully-fledged objects of specific types with corresponding, lower-level forms (and related form-based potentialities).

This approach follows a distinctively Aristotelian method of treating aporetic dilemmas: it resists a basic assumption which is shared by both horns of Sidelle's challenge and gives rise to the impasse. For, in this approach, there are not two spatiotemporally coincident objects at all. While matter by itself is not yet a proper object at all, yet matter enformed in the way characteristic of the compound just is (the same as) the compound. Similarly, other matter-like items, such as bricks or a corpse, are fully enformed compounds. It is only matter by itself which is less than an object in that it is (like) a determinable. Nor is there any implication that the form is, in this view, a separate object, over and above the compound, in which case the two distinct but spatiotemporally coincident objects would be the form and the compound. The form is an entity but is not an object. Rather, it is a determinant and a cause: what makes the matter and the compound what they are. More figuratively, the form is not an object but is how or why an object is as it is.

\section{The Matter-Form Relation}

Koslicki favours the model of mereological composition specified in terms of her RMHP. But is this model, even if modified in her preferred way, appropriate to capture the nuances of the Aristotelian matter-form relation? If we understand form as a part in exactly the same sense in which material constituents are parts, how are we to avoid Aristotle's celebrated infinite regress argument advanced in Metaphysics Z.17? If the putative principle 
of unity, the form, is a part alongside material parts, we shall need a further principle of unity for it and the material parts. But if the new principle of unity is again a part in the same way, we are led into an infinite regress. The same applies in the case where the putative principle of unity is not a part but is made of parts.

Moreover, this view of form as a 'strong', object-like part cannot tackle the question of how structured wholes such as hylomorphic compounds are unified, or are more unified than pluralities, sets, mere heaps, etc. Chapter 7 of Koslicki's book, which is dedicated to unity, may alleviate this worry. While her account of unity is attractive, the question still remains: can a form, understood as a 'strong' part, avoid the regress? Can it play the role of a unifier, even in Koslicki's considered view of unity?

Koslicki may reply that the form is of an entirely different ontological order if compared with the material constituents it unifies. Despite being a part, it is sufficiently different from material parts. Its different nature allows it to be a unifier without giving rise to any infinite regress. It is hard to see how this reply works, however, especially since Koslicki is explicitly non-committal about the ontological category forms belong to (see $§ 1$ ). She clearly rejects the idea that the form should be identified with either the compound or the matter. This may be a first step towards defusing the regress and unity worries about a 'strong' or 'mereological' object-like form. But it still falls short of offering a positive account of the form's ontological category and further features.

The mereological model is not the whole story. Koslicki's account of the matter-form relation enriches this model with the robust pluralist view. This view is designed to address the grounding problem and to escape the two horns of Sidelle's dilemma (see §1). Koslicki rejects the first horn of this dilemma using the robustness aspect of RMHP. The form is not understood as a non-robust entity which could be analysed in terms of such minimal 
conditions that could be satisfied by both the compound and the matter just in virtue of their being spatiotemporally coincident. Nor is it the case that the form can bear the very same relation -for example, belonging or predication- to both the compound and the matter, albeit in different ways (essentially to the compound and accidentally to the matter). Rather, the matter-form relation is that of matter's satisfying the constraints set by the form, whereas the compound-form relation is not identity but proper parthood, as implied by her mereological model. Therefore, in reply to the question 'in virtue of what does the form figure in the compound's essence but not in the matter's essence?' Koslicki contends that it is a basic fact that the form of (e.g.) Goliath, $f$, is essential just to Goliath, whereas Goliath's matter, Lumpl, has a different form, $f^{*}$, making up its essence. This gives rise to the pluralist claim that, while Goliath and Lumpl are spatiotemporally coincident, they are two numerically distinct objects. Koslicki, then, holds that the grounding question as it applies to the different essences of Goliath and Lumpl is misguided. Her non-modal conception of essence takes the difference of these two essences as primitive. On this assumption, it can derive and explain the different modal (necessary but non-essential) features of Goliath and Lumpl, thereby grounding the difference of these two objects. If so, her account can tackle the grounding problem.

A first, perhaps naive, question is whether her response offers a genuine solution to the grounding problem. The non-modal conception of essence takes essence as basic and grounds modal, necessary but non-essential, features on essence. But this is rather distinct from the primitivist assumption which takes it as a basic fact that Goliath's and Lumpl's essences are different. Once we assume this difference it is a trivial step to infer that Goliath and Lumpl are different, if spatiotemporally coincident, objects. If we embrace pluralism in this fashion, we can then straightforwardly derive and ground (in the essence-based way) 
further differences between Goliath and Lumpl. But isn't the initial, major question why or how Goliath's and Lumpl's essences, as well as Goliath and Lumpl themselves, are different?

Second, Koslicki's robust pluralism insists that there are two numerically distinct but spatiotemporally coincident objects, Goliath and Lumpl. The way in which the matter is picked up or described, however, is as 'Goliath's matter', 'the matter composing Goliath', 'the compound's matter', 'the matter composing the compound', and other similar phrases. Such phrases seem to be ambiguous as between the following two options:

(i) In characterising matter by using a name, a definite description, a demonstrative, etc. for the compound we construct a linguistic item that makes reference to some material item through, and in virtue of, referring to the compound. But, it may be claimed, this is not to refer to or describe matter by itself. Rather, it is to latch onto the compound 'under a different mode of presentation'. But, if so, why accept that Lumpl $\neq$ Goliath? Similarly, why think that Lumpl's essence $\neq$ Goliath’s essence? This would be another way to invoke the idea sketched in $\S 1$ that there is no difference between the matter thus-and-so enformed and the compound. This idea grows out of the causal-explanatory model of essence and form, first developed in the Posterior Analytics about processes (such as thunder or eclipse) and then extended to substances in Metaphysics Z.17-H. Thunder just is a certain noise in the clouds. Similarly, a human just is a living being made of bones, flesh, etc. arranged in a certain way. If we understand matter in this way, however, there is no reason to accept the presupposition underlying Sidelle's challenge that there are two different but spatiotemporally coincident objects, the matter and the compound. Nor is it necessary to opt for Koslicki's pluralism.

(ii) Perhaps our ways of picking up or describing matter genuinely latch onto matter by itself or as such. But is matter so understood a fully-fledged determinate type 
of object, as is presupposed by the singular term 'Lumpl'? Aristotle maintains that matter by itself is undefined, indeterminate, and unknowable (Z.10-11). Moreover, it is a mere potentiality, as opposed to the determinate actual being of form. It is potentially any one among a manifold of alternative (and normally incompatible) disjuncts: for instance, bronze is either an axe or a statue or a shield or... Again, in the causal-explanatory model some of us favour, this suggests that matter is (like) a determinable and so is not yet or as such a specific type of object. As noted in $\S 1$, this may entail that insofar as it is (like) a determinable, it is an abstract item, without any intrinsic (essential or accidental) features. If we understand matter in this way, however, it is clear that and why it is different from the compound. If so, the grounding problem does not arise at all. For, while the compound is a determinate type of object, the matter is not. Indeed, the matter is not a bona fide object at all but a mere abstract item, a potentiality, something indeterminate and merely determinable. This result is compatible with the setup of Sidelle's dilemma, in which Goliath $\neq$ Lumpl, as the determinable matter is indeed distinct from the determinate compound. But this non-identity is neither paradoxical nor unpalatable. For we are not strictly or properly speaking of two objects which are distinct but spatiotemporally coincident. Rather, the compound is an object but the matter is less than an object. There is nothing problematic in claiming that a sphere and a solid are spatiotemporally coincident but distinct: for the sphere is just a determinate way of being a solid, whereas being a solid is a mere determinable subsuming (inter alia) the sphere.

The upshot is that the notion of an object is problematic, especially as it applies to matter. Moreover, an Aristotelian hylomorphist need not concede that matter by itself is an extra, 
distinct, fully-fledged, determinate object that is spatiotemporally coincident with the compound.

Do Koslicki's mereological model and robust pluralism give a satisfactory account of the matter-form relation? I have already raised my doubts about the mereological aspect of RMHP. Robust pluralism adds to mereology the idea that form bears different relations to the compound and the matter. While it sets certain constraints to be satisfied by matter, it plays the role of a proper part of the structured whole that the compound is. Moreover, the matter has a form of its own, $f^{*}$, which is a proper part of it and of the compound. Despite being its proper part, however, $f^{*}$ does not figure in the compound's essence. One may think that this picture is underwhelming as it does not invoke Aristotle's idea that the primary substance, essence or form, is a cause and a principle for matter's being in a certain way (Z.17, 1041b59). Nor does this picture accommodate the role of form as a cause and a principle of the compound's being. Moreover, it may be thought that there is gap in Koslicki's robust pluralism. While she does not give a reductive account of the form's relation to the compound (indeed, she rejects the idea that such an account could be given), she explicates this relation in terms of the form's being a proper part of the compound. But if so, what is it that prevents the matter's form, $f^{*}$ in Koslicki's example, from figuring in the compound's essence too, given that $f^{*}$ is also a proper part of the compound (as Koslicki herself notes; $\mathrm{p}$. 118-119)? Perhaps there is a distinction to be made between being a merely spatiotemporal proper part and being an essential or essence-constituting proper part. But what is it that makes Lumpl's form, $f^{*}$, a proper part of Goliath only in the former sense but not in the latter? Moreover, is it an ad hoc move to insist that, while $f^{*}$ is a proper part of the compound (without figuring in its essence), the compound's form, $f$, is not even a proper part of the matter? 
An alternative view would insist that the form does not merely set constraints upon the matter, nor is it simply a proper part of the compound. Rather, the form is a cause and a principle for the matter's and the compound's being in a certain way. The question is whether this alternative can be developed without having to commit to non-robustness about form, i.e. the idea that the form has the very same relation to both the matter and the compound. Interpreters (myself included) who are optimistic about the causal-explanatory model of form, would return an affirmative response to this question. They think that the correct view of the matter-form relation employs the predicational model (the idea that the form is metaphysically predicated of matter) only as a springboard. While they hold that the form is related to matter (and indeed the compound) by way of essential predication, they understand essential predication as grounded in explanation, causation, and determination. The form makes matter and compounds what they essentially are by being a cause of their being in some or other among the four Aristotelian causal routes. In the central, substance case, especially for living beings, the relevant causal link is teleological. The essence or form answers the 'what is it?' and the 'why is it (as it is)?' questions at the same time and in the same way. Moreover, the form is a determinant which makes the merely determinable matter a determinate type of thing -the determinate hylomorphic compound.

This view, arguably, avoids a non-robust conception of form: the form-matter relation is different from the form-compound relation. Let us return to the analogy with determinates, determinables, and determinants. The idea is that the form stands to matter as the determinant (e.g., being equidistant from the centre) stands to the determinable (solid). By contrast, it stands to the compound as the determinant (being equidistant from the centre) stands to the determinate (sphere). Admittedly this may seem too thin to undergird the difference between the form-matter and the form-compound relations. But the causal-explanatory model also invokes the claim that the form, as a cause and determinant, is what 'causally acts on' the 
matter. Put differently, the matter is a sort of 'causal patient' operated upon by the form's causal and determinant role. By contrast, the form is the cause that yields the compound as a sort of 'causal effect'. The compound, then, is the 'causal output' of the form's causally acting upon, and determining, the matter. In a slightly different formulation, the form is the cause that brings on the presence of (an) effect-like feature(s) in the matter. The compound just is that feature's being present in the matter. For example, being for the sake of protecting humans and their belongings from adverse weather conditions (the form of a house, identified with the final cause) is what 'brings on' the presence of the covering structure in the bricks, stones, mortar etc. (the matter). The house (a compound) is identified with the covering structure's being present in the bricks, stones, mortar, etc. Similarly, being for the sake of a certain sort of rational life (the form of a human, again identified with the final cause) is the cause of a characteristic arrangement's belonging to bones, flesh, etc. (the matter). The compound human just is a living being in which such an arrangement belongs to bones, flesh, etc.

Two remarks are in order. First, the causal talk in phrases such as 'causally acts on', 'is a causal patient', 'causal effect', 'to bring on', etc. should be understood broadly. It is not restricted to cases of Humean or merely efficient causation. Rather, it extends to all four types of Aristotelian cause. Second, while the cases of artefacts, such as Goliath or a house, are helpful illustrations of, and indeed may be understood as, compounds, they are not substance compounds. They cannot, therefore, fulfil the stringent requirements for unity and primacy imposed on substance compounds -paradigmatically living beings such as plants and animals.

Before closing it is important to note that, while I focused on disagreements with and objections to her argument, Koslicki's view contains a lot of ideas which we should find ourselves congenial to. Her book is indispensable not only for the modern Neo-Aristotelian 
metaphysician or for Aristotle scholars but also for anyone who wishes to think seriously about questions of essence, identity, constitution, persistence, and modality.

MICHAIL PERAMATZIS

Worcester College, Oxford University

michail.peramatzis@philosophy.ox.ac.uk 